Ciência Florestal, Santa Maria, v. 21, n. 4, p. 699-710, out.-dez., 2011

ISSN 0103-9954

\title{
PRODUÇÃO DE SERAPILHEIRA E RETORNO DE MACRONUTRIENTES EM TRÊS GRUPOS FLORÍSTICOS DE UMA FLORESTA OMBRÓFILA MISTA, RS
}

\author{
LITTER PRODUCTION AND MACRONUTRIENTS RETURN IN THREE FLORISTIC \\ GROUPS OF AN ARAUCARIA FOREST, RS STATE
}

\author{
Régis Villanova Longhi ${ }^{1}$ Solon Jonas Longhi ${ }^{2}$ Luciane Belmonte Chami ${ }^{3}$ \\ Luciano Farinha Watzlawick ${ }^{4}$ Angelo Augusto Ebling ${ }^{5}$
}

\begin{abstract}
RESUMO
O objetivo do presente estudo foi avaliar a produção de serapilheira e o retorno de macronutrientes em três grupos florísticos, ocorrentes na Floresta Ombrófila Mista, localizada na FLONA de São Francisco de Paula, RS. Para isso, utilizou-se três conglomerados permanentes de 1 ha $(100 \times 100 \mathrm{~m})$ cada, onde a vegetação foi previamente classificada, por análise de agrupamento, em três distintos grupos florísticos: GF1 - Floresta Secundária de Encosta; GF2 - Floresta Ombrófila Mista Típica; e GF3 - Floresta de Locais Úmidos. Para a coleta dos dados foram distribuídos, sistematicamente, 16 coletores de serapilheira de $1 \mathrm{~m}^{2}$ de área, por grupo florístico. O material, recolhido mensalmente durante um ano, foi separado nas seguintes frações: folhas de folhosas, grimpas, galhos, miscelânea e sementes. Para a análise química dos macronutrientes - nitrogênio $(\mathrm{N})$, fósforo $(\mathrm{P})$, potássio $(\mathrm{K})$, cálcio $(\mathrm{Ca})$, magnésio $(\mathrm{Mg})$ e enxofre $(\mathrm{S})$ - contidos na serapilheira depositada, foram considerados os grupos florísticos, as frações e as estações climáticas. A produção anual de serapilheira foi de $8.354,4 \mathrm{~kg} \mathrm{ha}^{-1}$, 7.927,5 kg.ha-1 e 7.017,8 kg.ha-1 nos grupos GF2, GF1 e GF3, respectivamente. Nos grupos GF1 e GF3, a primavera foi a estação que apresentou a maior deposição, seguida pelo verão, inverno e outono. O GF2 apresentou maior deposição no verão, seguido da primavera, outono e inverno. As frações folhas de folhosas e grimpas constituíram no principal componente, respondendo também pelo maior retorno de macronutrientes. O retorno total estimado de macronutrientes foi de 358,57 kg.ha- ${ }^{-1}$ ano ${ }^{-1}$, 284,25 kg.ha- . $^{-1}$ e 256,80 kg.ha ${ }^{-1}$. ano ${ }^{-1}$ para os grupos GF2, GF3 e GF1, respectivamente. A ordem da transferência dos macronutrientes presentes na serapilheira depositada foi: $\mathrm{N}>\mathrm{Ca}>\mathrm{K}>\mathrm{Mg}>\mathrm{S}>\mathrm{P}$, para os grupos GF1 e GF2; e $\mathrm{Ca}>\mathrm{N}>\mathrm{K}>\mathrm{Mg}>\mathrm{S}>\mathrm{P}$, para o GF3.
\end{abstract}

Palavras-chave: floresta com araucária; ecologia; nutrição florestal.

\begin{abstract}
The aim of the current study was to evaluate the production of litter and the return of macronutrients in three floristic groups which occur in the Araucaria Forest, located in the National Forest of São Francisco de Paula, RS state. For this purpose, we selected three permanent conglomerates of 1 ha (100x 100m) each one, where the vegetation was previously classified, by cluster analysis, in three different floristic groups: FG1 hillside environment; FG2 - typical araucaria forest; and FG3- humid environment. For litter fall collection, 16 litter traps of $1 \mathrm{~m}^{2}$ of area were distributed, systematically, by floristic group. The material was collected monthly during one year and separated in the following fractions: leaves, araucaria needles, branches,
\end{abstract}

1. Engenheiro Florestal, Mestrando do Programa de Pós-graduação em Engenharia Florestal, Centro de Ciências Rurais, Universidade Federal de Santa Maria, Av. Roraima, 1000, CEP 97105-900, Santa Maria (RS). regislonghi@yahoo.com.br

2. Engenheiro Florestal, Dr., Professor do Departamento de Ciências Florestais, Universidade Federal de Santa Maria, Av. Roraima, 1000, CEP 97105-900, Santa Maria (RS).solon.longhi@gmail.com

3. Engenheira Florestal, MSc., Centro de Ciências Rurais, Universidade Federal de Santa Maria, Av. Roraima, 1000, CEP 97105-900, Santa Maria (RS).1chami@terra.com.br

4. Engenheiro Florestal. Dr., Professor do Departamento de Agronomia, Universidade Estadual do Centro-Oeste, Rua Camargo Varela de Sá, 03, CEP 85040-080, Guarapuava (PR). luciano.watzlawick@pq.cnpq.br

5. Engenheiro Florestal, Mestrando do Programa de Pós-graduação em Ciências Florestais, Universidade Estadual do Centro-Oeste, Rua Camargo Varela de Sá, 03, CEP 85040-080, Guarapuava (PR). aebling@hotmail.com

Recebido para publicação em 2/03/2010 e aceito em 25/10/2010 
miscellaneous and seeds. For the chemical analysis of the macronutrients - nitrogen (N), phosphorus (P), potassium $(\mathrm{K})$, calcium $(\mathrm{Ca})$, magnesium $(\mathrm{Mg})$ and sulfur $(\mathrm{S})$ - returned in litter, we considered the floristic groups, the fractions and the climatic seasons. The annual production of litter was $8.354,4 \mathrm{~kg} \cdot \mathrm{ha}^{-1} \cdot \mathrm{yr}^{-1}$, 7.929,5 kg.ha-1. $\mathrm{yr}^{-1}$ and $\mathrm{kg} \cdot \mathrm{ha}^{-1} \cdot \mathrm{yr}^{-1}$ in the groups FG2, FG1 and FG3, respectively. For the FG1 and FG3 groups, spring was the season that presented the highest litter deposition, followed by summer, winter and autumn. The FG2 group showed the highest litter deposition in summer, followed by spring, autumn and winter. The fractions of leaves and araucaria needles formed the main litter component, responding also by a higher return of macronutrients. The estimated litter return of macronutrients were of $358,57 \mathrm{~kg}^{-h^{-1}} \cdot \mathrm{yr}^{-1}$ and 256,80 kg.ha- $\mathrm{yr}^{-1}$ for the groups FG2, FG3 and FG1, respectively. The order of transference of those macronutrients present in the deposited litter was: $\mathrm{N}>\mathrm{Ca}>\mathrm{K}>\mathrm{Mg}>\mathrm{S}>\mathrm{P}$, for the groups FG1 and FG2; and $\mathrm{Ca}>\mathrm{N}>\mathrm{K}>\mathrm{Mg}>\mathrm{S}>\mathrm{P}$, for the GF3.

Keywords: araucaria forest; ecology; forest nutrition.

\section{INTRODUÇÃO}

No Rio Grande do Sul, Brasil, os remanescentes de Floresta Ombrófila Mista (FOM) se encontram na natureza formando mosaicos em distintas fases de sucessão e altamente descaracterizados em relação à estrutura e florística original. As áreas que mantiveram sua estrutura e composição de espécies próxima das características originais são de fundamental importância à pesquisa, pois representam o que restou das florestas primárias.

Na última década, o crescente interesse da ciência quanto ao funcionamento dos ecossistemas florestais naturais brasileiros, observado nas inúmeras pesquisas já realizadas, possui a finalidade de subsidiar e orientar ações futuras de restauração, conservação e manejo sustentável destes locais. $\mathrm{Na}$ Floresta Nacional (FLONA) de São Francisco de Paula, o Projeto Ecológico de Longa Duração (PELD) vem desenvolvendo no ecossistema Floresta Ombrófila Mista diversos estudos abordando crescimento, estrutura, dinâmica da vegetação e suas inter-relações com o meio, merecendo destaque os trabalhos desenvolvidos por Longhi et al. (2006), Ribeiro et al. (2007), Chami (2008), Gomes et al. (2008), Narvaes et al. (2008) e Longhi et al. (2010).

Para manejar racionalmente qualquer formação florestal, Sanquetta et al. (2001) entendem que é fundamental que se disponha de conhecimento básico de estrutura e dinâmica das populações, suas relações e funções ecológicas, produtividade primária, entre outros. Uma das causas do manejo inadequado das florestas é o desconhecimento dos fatores que sustentam a alta produção de biomassa e, ainda, concomitantemente, que conservam a fertilidade do solo (CALDEIRA et al., 2008). Nesse contexto, o conhecimento sobre a produção da serapilheira e a ciclagem de nutrientes é primordial para um melhor entendimento da dinâmica nutricional no ecossistema, uma vez que, para Golley (1975), a liberação de nutrientes pela serapilheira depositada é considerada o meio mais importante de transferência de nutrientes da vegetação para o solo.

A serapilheira pode ser definida como todo material vegetal recém-caído na parte superficial do piso da floresta, constituído de folhas, fragmentos de casca, galhos, flores, inflorescências, frutos (KOEHLER, 1989), além de restos vegetais não identificáveis. Para Caldeira et al. (2007), o acúmulo de serapilheira varia com a espécie, a cobertura florestal, o estágio sucessional, a idade, a época da coleta, o tipo de floresta e o local; bem como, consideram as condições edafoclimáticas e regime hídrico, de sítio, sub-bosque, manejo silvicultural, como fatores que também influenciam no seu acúmulo no solo. Para Moreira e Siqueira (2002), o tipo de vegetação e as condições ambientais são os fatores que mais influem na quantidade e qualidade do material que cai no solo.

Assim que é depositada sobre o solo, a serapilheira é submetida a um processo de decomposição que se inicia com a ação da fauna edáfica, constituída, sobretudo, de artrópodes, que têm como principal função a degradação do material para que este seja posteriormente decomposto pelos micro-organismos e, ao final do processo, haja a liberação gradativa dos nutrientes minerais que são constituintes dos tecidos orgânicos (GOLLEY et al., 1978). Dessa forma, o material orgânico que é depositado continuamente sobre o solo assume importância indiscutível na manutenção da fertilidade e dos níveis de nutrientes no solo (CALVI et al., 2009).

Além da importância nutricional, a deposição de serapilheira sobre o solo pode ocasionar a interceptação de luz, sombreando sementes e

Ci. Fl., v. 21, n. 4, out.-dez., 2011 
plântulas, reduzindo a amplitude térmica do solo e, assim, criando uma barreira à difusão do vapor d'água, reduzindo a evaporação do solo. Por outro lado, pode também reduzir a disponibilidade hídrica, retendo uma considerável proporção de água da chuva que chegaria ao solo e também impedir a chegada de algumas sementes, dificultando o crescimento de plântulas (FACELLI e PICKETT, 1991).

Delitti (1984) mencionou dois padrões básicos para a deposição anual de serapilheira: o primeiro se refere a uma maior deposição na época seca, estando diretamente ligado à quantidade $\mathrm{e}$ disponibilidade de água no solo, causando um estresse hídrico e, consequentemente, a senescência do vegetal; o segundo caso é o contrário e consiste em um aumento na intensidade de deposição de serapilheira na época úmida, devido ao impacto mecânico provocado pelas chuvas e pelos ventos, provocando um aumento na taxa de deposição.

De acordo com Bray e Gorhan (1964), a quantia de material orgânico, depositado ao longo de um ano, em florestas, é menor nas regiões frias e maior nas regiões equatoriais quentes e úmidas, sendo que, florestas situadas em regiões árticas e alpinas produzem, anualmente, cerca de $1 \mathrm{Mg} /$ ha de serapilheira; florestas temperadas frias, 3,5 $\mathrm{Mg} / \mathrm{ha}$; florestas temperadas quentes, $5,5 \mathrm{Mg} /$ ha e florestas equatoriais, cerca de $11 \mathrm{Mg} / \mathrm{ha}$. Nas Florestas Ombrófilas no Sul do Brasil, vários autores encontraram valores variando de 5,2 Mg.ha- ${ }^{-1}$ a 11,2 Mg.ha- ${ }^{-1}$ (BRITEZ et al., 1992; BRITEZ, 1994; FLOSS et al., 1999; FIGUEIREDO FILHO et al., 2003; BACKES et al., 2005; CALDEIRA et al., 2007).

Em relação às diferentes frações que compõem a serapilheira depositada, Bray e Gorham (1964) afirmam que, de maneira geral, a serapilheira é composta de 60 a $80 \%$ de folhas, 1 a $15 \%$ de ramos e 1 a $25 \%$ de casca. Por conseguinte, Caldeira et al. (2007) afirmam que as folhas da serapilheira são responsáveis pelo retorno da maior quantidade de nutrientes ao solo, devido mais às quantidades de folhas depositadas do que aos teores dos elementos. Vitousek (1984), baseando-se na concentração de nutrientes da serapilheira em diferentes florestas do mundo, sugere ser o nitrogênio e o fósforo os elementos mais limitantes nas florestas temperadas e tropicais, respectivamente.

Diante do exposto, com o intuito de auxiliar no entendimento do funcionamento do Ecossistema Floresta com Araucária, esse trabalho teve como objetivo avaliar eventuais diferenças na produção anual e estacional de serapilheira, bem como do retorno de macronutrientes $(\mathrm{N}, \mathrm{P}, \mathrm{K}, \mathrm{Ca}, \mathrm{Mg}$ e $\mathrm{S}$ ) em três grupos florísticos - Floresta Secundária de Encosta; Floresta Ombrófila Mista Típica e Floresta de Locais Úmidos - ocorrentes na Floresta Ombrófila Mista da Floresta Nacional de São Francisco de Paula, RS.

\section{MATERIAL E MÉTODOS}

\section{Área de Estudo}

O estudo foi realizado na Floresta Nacional (FLONA) de São Francisco de Paula, localizada no nordeste no estado do Rio Grande do Sul, na serra gaúcha, microrregião dos Campos de Cima da Serra, entre as coordenadas geográficas $29^{\circ} 23^{\prime}$ e $29^{\circ} 27^{\prime}$ de latitude Sul e $50^{\circ} 23^{\prime}$ e $50^{\circ} 25^{\prime}$ de longitude Oeste, a uma altitude máxima de 930 metros.

A FLONA possui uma área total de 1.606,6 ha. Destes, cerca de 56\% são compostos por floresta nativa, pertencente à Floresta Ombrófila Mista, conhecida também como Floresta com Araucária. Além da Araucaria angustifolia (Bertol.) Kuntze, que imprime o caráter fisionômico dessa vegetação, são comuns e características da formação as seguintes espécies arbóreas: Ilex paraguariensis A.St.-Hil., Matayba elaeagnoides Radlk., Dicksonia sellowiana Hook., Blepharocalyx salicifolius (Kunth) O. Berg, Nectandra megapotamica (Spreng.) Mez, Lithraea brasiliensis Marchand, Cryptocarya aschersoniana Mez, Ilex brevicuspis Reissek, Campomanesia xanthocarpa O.Berg, Myrcianthes gigantea (D. Legrand) D. Legrand, entre outras (RIO GRANDE DO SUL, 2002).

O clima na região, de acordo com a classificação climática de Köppen, é do tipo temperado $\mathrm{Cfb}$, mesotérmico médio, apresentando valores médios anuais de temperatura inferiores a $22^{\circ} \mathrm{C}$ no mês mais quente e, entre $-3^{\circ} \mathrm{C}$ e $18^{\circ} \mathrm{C}$, no mês mais frio (MORENO, 1961). É frequente a formação de geadas, com eventual ocorrência de neve. Nevoeiros são frequentes devido à altitude e a proximidade com a borda do planalto, chegando a mais de 90 dias por ano de ocorrência. Segundo o $8^{\circ}$ Distrito de Meteorologia em São Francisco de Paula chove, em média, $2.252 \mathrm{~mm}$ por ano. No período referente ao presente estudo, de acordo com dados extraídos de relatório não publicado da própria FLONA(IBAMA/ ICMBio, 2008), foi observada precipitação anual de $1.860,5 \mathrm{~mm}$, distribuída pelas estações do ano da seguinte forma: verão $(467,5 \mathrm{~mm})$, outono $(360,5$ $\mathrm{mm})$, inverno $(598,0 \mathrm{~mm})$ e primavera $(434,5 \mathrm{~mm})$. 
O solo da área de estudo é do tipo Cambissolo, comum em locais onde ocorre elevada precipitação e baixas temperaturas que favorecem o acúmulo de matéria orgânica. Cambissolos apresentam forte acidez e baixa disponibilidade de nutrientes (STRECK et al., 2008).

\section{Amostragem e coleta dos dados}

A coleta de serapilheira foi realizada em três conglomerados permanentes de 1 ha $(100 \mathrm{x}$ $100 \mathrm{~m}$ ) cada, constituintes do PELD-CNPq (Projeto Ecológico de Longa Duração - financiado pelo Conselho Nacional de Desenvolvimento Científico e Tecnológico), que foram parte da estrutura amostral utilizada por Chami (2008) em estudo de agrupamento da vegetação e chuva de sementes. $\mathrm{Na}$ análise de agrupamento da vegetação, Chami (2008) subdividiu, sistematicamente, cada um desses conglomerados, em 16 parcelas de $20 \mathrm{~m} \times 20 \mathrm{~m}$, mantendo-se $10 \mathrm{~m}$ de bordadura (Figura 1a). No centro de cada uma dessas parcelas foi alocado um coletor de serapilheira, totalizando 48 coletores nos três conglomerados amostrais utilizados no presente estudo. Os coletores de serapilheira, com formato circular e $1 \mathrm{~m}^{2}$ de área, foram confeccionados com canos de PVC, ferro e tecido (malha inferior a $1 \mathrm{~mm}$ ), e dispostos a, aproximadamente, $1 \mathrm{~m}$ da superfície do solo (Figura $1 b$ ).

Para a avaliação da deposição de serapilheira e retorno de macronutrientes, consideraram-se os três grupos florísticos determinados por Chami (2008), por meio do método TWINSPAN (Two-way Indicator Species Analysis), que verifica a ocorrência de padrões na distribuição das espécies, associados às características locais. Os agrupamentos obtidos foram: Grupo Florístico 1 no qual se destacou Siphoneugena reitzii, caracterizando um ambiente de encosta; Grupo Florístico 2, onde se destacou Arancaria angustifolia, caracterizando um ambiente com dossel dominado por indivíduos de grande porte dessa espécie; e Grupo Florístico 3 com predominância de Sebastiania commersoniana, descrevendo um ambiente úmido. Cada conglomerado apresentou todas as suas 16 parcelas pertencentes a um dos distintos grupos florísticos.

No presente estudo, os grupos foram denominados de Floresta Secundária de Encosta (GF1), Floresta Ombrófila Mista Típica (GF2) e Floresta de Locais Úmidos (GF3). Essas denominações deram-se por observações visuais em cada área amostral, tendo-se como base a classificação pelo método TWISPAN determinada por Chami (2008).

As coletas foram realizadas mensalmente, durante o período de fevereiro de 2007 a janeiro de 2008, constituindo 12 coletas. Após cada coleta, o material de cada coletor foi separado nas frações: folhas de folhosas, grimpas (ramos aciculados da

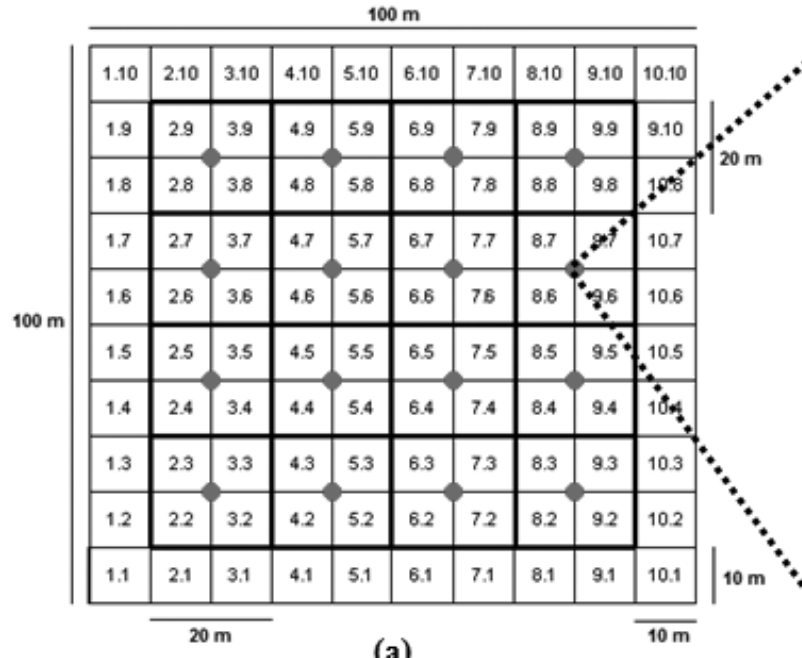

(a)

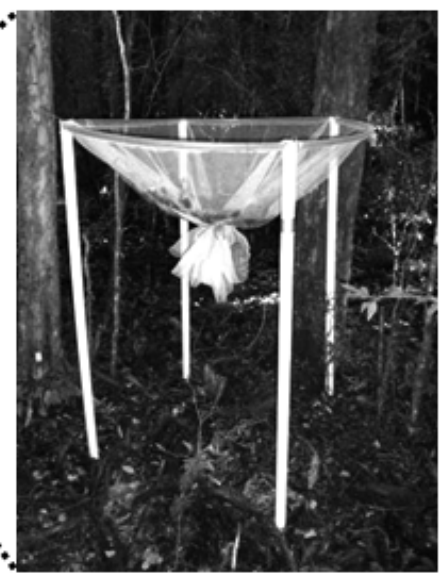

(b)

FIGURA 1: Esquema de um conglomerado e suas subunidades, representando a disposição dos coletores de serapilheira na parcela (a) e na mata (b). Floresta Ombrófila Mista, FLONA de São Francisco de Paula, RS.

FIGURE 1: Outline of a conglomerate and its subunits, representing the disposition of the collectors of litter in the plot (a) and in the forest (b). Araucaria Forest, National Forest of São Francisco de Paula, RS state. 
conífera Araucaria angustifolia), galhos, sementes e miscelâneas (flores, frutos, materiais que não se conseguiu identificar e materiais de origem animal); essas foram embaladas em sacos de papel e levadas à estufa a uma temperatura entre $60-70^{\circ} \mathrm{C}$, até atingirem peso constante. Com base nos dados de peso seco de cada fração estimou-se a produção mensal de serapilheira, em kg.ha- ${ }^{-1} \cdot \mathrm{mês}^{-1}$, e após, somadas para se obter a devolução anual de serapilheira, em kg.ha ${ }^{-1}$. ano $^{-1}$, para o piso florestal.

Para determinação da concentração dos macronutrientes - nitrogênio $(\mathrm{N})$, fósforo $(\mathrm{P})$, potássio $(\mathrm{K})$, cálcio $(\mathrm{Ca})$, magnésio $(\mathrm{Mg})$ e enxofre $(\mathrm{S})$ - nas frações da serapilheira, as amostras foram separadas por tipo de fração e por estação do ano, em cada grupo florístico. Este material foi moído em moinho tipo Wiley, com peneira de 30 mesh, e posteriormente analisado de acordo com a metodologia padrão do Laboratório de Ecologia Florestal da UFSM, descrita em Tedesco et al. (1995). A quantidade de nutrientes que retorna ao piso florestal via serapilheira foi estimada multiplicando-se a concentração do nutriente, na estação climática, pela quantidade de fitomassa depositada, para cada fração, nessa estação.

Foi realizada uma caracterização da vegetação arbórea ocorrente em cada grupo florístico, com a finalidade de correlacionar a estrutura da floresta com a produção de serapilheira. Para essa caracterização, foram considerados apenas os indivíduos arbóreos com diâmetro a altura do peito (DAP) $\geq 10 \mathrm{~cm}$. Os dados foram obtidos por meio de consulta ao banco de dados do projeto PELD-CNPq.

A análise estatística utilizada para avaliar a produção das frações de serapilheira nos grupos florísticos e a produção estacional de serapilheira, foi baseada em um arranjo fatorial, composto por três fatores ( $\mathrm{F} 1=$ Grupo Florístico; $\mathrm{F} 2=$ Estação do Ano; F3=Fração de serapilheira) e 16 repetições. A fração sementes foi desconsiderada da análise por não possuir dados de cada coletor, mas sim para toda a parcela. Já as diferenças nas concentrações e transferências de nutrientes, foram verificadas por delineamento inteiramente casualizado, utilizandose como repetições as estações do ano. Todas as análises estatísticas foram realizadas com auxílio do programa ASSISTAT Versão 7.5 beta (2008), desenvolvido por Silva e Azevedo (2002), e as médias foram comparadas pelo teste de Tukey, a $5 \%$ de significância.

\section{RESULTADOS E DISCUSSÃO}

\section{Características da vegetação dos grupos florísticos}

A estrutura do componente arbóreo possui influência na produção de serapilheira, fato este é comprovado por Pinto et al. (2009) que ao estudar a ciclagem de nutrientes em dois trechos de Floresta Estacional Semidecidual em Viçosa, MG, encontraram maior produção de serapilheira em uma floresta madura que apresentou a área basal e densidade muito superior a floresta inicial.

A caracterização da vegetação arbórea ocorrente em cada grupo florístico está representada na Tabela 1. Não foram observadas diferenças estatísticas em relação à área basal total amostrada entre os grupos florísticos. A Floresta Secundária de Encosta apresentou maior densidade de indivíduos, enquanto que a Floresta de Locais Úmidos teve o menor número de indivíduos amostrados. Contudo, em relação à densidade e à área basal de araucária, esses dois grupos florísticos não apresentaram diferenças estatísticas, diferindo apenas com a FOM Típica, a qual teve aproximadamente $80 \%$ da área basal desse grupo florístico composto pela araucária.

TABELA 1: Caracterização da vegetação com diâmetro à altura do peito (DAP) $\geq 10 \mathrm{~cm}$ ocorrente nos grupos florísticos na FLONA de São Francisco de Paula, RS, 2007.

TABLE 1: Characterization of vegetation with $\mathrm{DBH} \geq 10 \mathrm{~cm}$ contained in the floristic groups in the National Forest of São Francisco de Paula, RS state, 2007.

\begin{tabular}{lccc}
\hline & Floresta Secundária de Encosta & FOM Típica & Floresta de Locais Úmidos \\
\hline N. de parcelas amostradas & $16\left(6.400 \mathrm{~m}^{2}\right)$ & $16\left(6.400 \mathrm{~m}^{2}\right)$ & $16\left(6.40 \mathrm{~m}^{2}\right)$ \\
N. de indivíduos amostrados & $618^{\mathrm{a}}$ & $539^{\mathrm{ab}}$ & $439^{\mathrm{b}}$ \\
Área basal amostrada $\left(\mathrm{m}^{2}\right)$ & $28,1^{\mathrm{a}}$ & $33,5^{\mathrm{a}}$ & $27,8^{\mathrm{a}}$ \\
N. de indivíduos de araucária & $20^{\mathrm{b}}$ & $210^{\mathrm{a}}$ & $18^{\mathrm{b}}$ \\
Área basal de araucária $\left(\mathrm{m}^{2}\right)$ & $3,9^{\mathrm{b}}$ & $26,6^{\mathrm{a}}$ & $2,0^{\mathrm{b}}$ \\
\hline
\end{tabular}

Em que: Valores seguidos da mesma letra minúscula, na horizontal, não diferem estatisticamente entre si pelo teste de Tukey ao nível de 5\% de probabilidade. FONTE: Banco de dados PELD-CNPq. Dados não publicados. 


\section{Produção de Serapilheira}

Em todos os grupos florísticos, a produção total anual de serapilheira não apresentou diferença estatística, alcançando, valores de 8.354,4 kg.ha- ${ }^{-1}$. ano $^{-1}$ para o grupo FOM Típica, 7.927,5 kg.ha ${ }^{-1}$. ano $^{-1}$ no grupo Floresta Secundária de Encosta e 7.017,8 kg.ha- ${ }^{-1}$. ano ${ }^{-1}$ no grupo Floresta de Locais Úmidos (Tabela 2). Esses valores estão próximos aos encontrados por Floss et al. (1999), que ao estudar a deposição de serapilheira em duas áreas com Floresta Ombrófila Mista na Reserva Florestal de Caçador-SC, observaram uma produção de $8.348 \mathrm{~kg} \cdot \mathrm{ha}^{-1} \cdot$ ano $^{-1}$ para a fisionomia florestal com predomínio de Araucaria angustifolia e de 7.335 $\mathrm{kg} \cdot \mathrm{ha}^{-1} \cdot$ ano $^{-1}$ para a fisionomia onde predominam espécies de folhosas. Figueiredo Filho et al. (2003) relataram produção anual média de $7.736,8 \mathrm{~kg} \cdot \mathrm{ha}^{-1}$ de serapilheira em uma Floresta Ombrófila Mista Montana que sofreu intensa exploração seletiva de araucária no passado.

A fração folhas constituiu a maior parte da serapilheira produzida para a Floresta Secundária de Encosta e para a Floresta de Locais Úmidos, representando, respectivamente, $48,5 \%$ e $61,2 \%$ do total de serapilheira produzida (Tabela 2). Em uma Floresta Ombrófila Mista em Iratí-PR, Figueiredo Filho et al. (2005) verificaram que a fração folhas correspondeu a $41,7 \%$ da produção total de serapilheira.

A produção da fração grimpas mostrou-se bastante variada nos grupos florísticos, diferindo estatisticamente entre eles. Na FOM Típica, a qual apresenta dossel dominado pela conífera Araucaria angustifolia, a fração grimpas foi responsável por cerca de $54 \%$ da produção total de serapilheira. Por outro lado, na Floresta de Locais Úmidos, essa mesma fração representou apenas $7,6 \%$ da produção total. Essa discrepância pode ser explicada pela grande diferença estrutural entre esses dois grupos, uma vez que a Floresta de Locais Úmidos apresentou apenas 18 indivíduos de Araucaria angustifolia no conglomerado avaliado, representando área basal de $2 \mathrm{~m}^{2}$. Já na FOM Típica foram amostrados 210 indivíduos dessa espécie, contribuindo com $26,6 \mathrm{~m}^{2}$ de área basal e, assim, com produção mais alta de grimpas.

Em relação à quantificação das demais frações de serapilheira (galhos, sementes e miscelânea), não foi observada diferença estatística das produções entre os grupos florísticos.

A análise da produção estacional de serapilheira entre os grupos florísticos (Tabela 3) mostrou que os grupos Floresta Secundária de Encosta e Floresta de Locais Úmidos apresentaram o mesmo comportamento quanto ao total de serapilheira produzida, seguindo a ordem: primavera $>$ verão $>$ inverno $>$ outono. No grupo FOM Típica, a produção mostrou-se maior no verão $>$ primavera $>$ outono $>$ inverno. Diversos autores também verificaram comportamentos parecidos com o presente estudo. Backes et al. (2005), na mesma Floresta Nacional em estudo, encontraram maior produção na primavera e menor no inverno. Floss et al. (1999), estudando duas tipologias em Floresta Ombrófila Mista, observaram maior produção durante a primavera e verão. Caldeira et al. (2008), em três estágios sucessionais da Floresta Ombrófila Densa Submontana em Blumenau-SC, encontraram a maior produção de serapilheira no verão para todos os estágios.

A maior produção nas estações úmidas, primavera e verão, é típica das regiões tropicais e

TABELA 2: Produção de serapilheira $\left(\mathrm{kg} \cdot \mathrm{ha}^{-1} \cdot \mathrm{ano}^{-1}\right)$ por fração e por grupo florístico para uma Floresta Ombrófila Mista (FOM). FLONA de São Francisco de Paula, RS.

TABLE 2: Litter production ( $\left.\mathrm{kg} \cdot \mathrm{ha}^{-1} \cdot \mathrm{ano}^{-1}\right)$ by fraction and by floristic group for an Araucaria Forest. National Forest in São Francisco de Paula, RS state.

\begin{tabular}{l|c|c|c|c|c|c}
\hline Fração de & \multicolumn{2}{|c|}{ Floresta Sec. de Encosta } & \multicolumn{2}{c|}{ FOM Típica } & \multicolumn{2}{c}{ Floresta de Locais Úmidos } \\
\cline { 2 - 7 } Serapilheira & $\mathrm{kg}^{-} \cdot \mathrm{a}^{-1} \cdot \mathrm{ano}^{-1}( \pm$ desvio $)$ & $\%$ & kg.ha-1.ano-1 $( \pm$ desvio $)$ & $\%$ & kg.ha-1.ano-1 $( \pm$ desvio $)$ & $\%$ \\
\hline Folhas & $3.846,6^{\mathrm{a}}( \pm 135,3)$ & 48,5 & $1.802,1^{\mathrm{b}}( \pm 57,8)$ & 21,6 & $4.291,6^{\mathrm{a}}( \pm 172,1)$ & 61,2 \\
Grimpas & $1.751,6^{\mathrm{b}}( \pm 121,7)$ & 22,1 & $4.499,2^{\mathrm{a}}( \pm 202,6)$ & 53,8 & $534,3^{\mathrm{c}}( \pm 48,0)$ & 7,6 \\
Galhos & $1.078,5^{\mathrm{a}}( \pm 74,0)$ & 13,6 & $582,3^{\mathrm{a}}( \pm 27,3)$ & 7,0 & $1.303,4^{\mathrm{a}}( \pm 48,0)$ & 18,6 \\
Sementes & $248,1^{\mathrm{a}}( \pm 21,4)$ & 3,1 & $241,8^{\mathrm{a}}( \pm 29,9)$ & 2,9 & $114,9^{\mathrm{a}}( \pm 12,0)$ & 1,6 \\
Miscelânea & $1.002,6^{\mathrm{a}}( \pm 42,0)$ & 12,6 & $1.229,0^{\mathrm{a}}( \pm 65,4)$ & 14,7 & $773,6^{\mathrm{a}}( \pm 31,2)$ & 11,0 \\
\hline Total & $7.927,5^{\mathrm{a}}( \pm 260,4)$ & 100 & $8.354,4^{\mathrm{a}}( \pm 272,2)$ & 100 & $7.017,8^{\mathrm{a}}( \pm 188,7)$ & 100 \\
\hline
\end{tabular}

Em que: Valores seguidos da mesma letra, na horizontal, não diferem estatisticamente entre si pelo teste de Tukey ao nível de 5\% de probabilidade; \pm desvio referente à produção mensal de serapilheira, considerando-se 12 repetições.

Ci. Fl., v. 21, n. 4, out.-dez., 2011 
TABELA 3: Produção estacional de serapilheira em três grupos florísticos ocorrentes na FLONA de São Francisco de Paula, RS, 2007.

TABLE 3: Season production of litter in three floristic groups occurring in the National Forest of São Francisco de Paula, RS state, 2007.

\begin{tabular}{l|c|c|c|c}
\hline \multirow{2}{*}{ Grupo Florístico } & \multicolumn{4}{|c}{ Estação Climática } \\
\cline { 2 - 5 } & Verão & Outono & Inverno & Primavera \\
\hline Floresta Secundária de Encosta & $2088,0^{\mathrm{AB}} \mathrm{ab}$ & $1275,9^{\mathrm{Ab}}$ & $1907,4^{\mathrm{Aab}}$ & $2656,1^{\mathrm{Aa}}$ \\
FOM Típica & $2662,6 \mathrm{Aa}$ & $1878,5^{\mathrm{Abc}}$ & $1384,1^{\mathrm{Ac}}$ & $2429,2^{\mathrm{Aab}}$ \\
Floresta de Locais Úmidos & $1598,6 \mathrm{~B} \mathrm{~b}$ & $1466,4^{\mathrm{Ab}}$ & $1509,3^{\mathrm{Ab}}$ & $2443,6^{\mathrm{Aa}}$ \\
\hline
\end{tabular}

Em que: FOM = Floresta Ombrófila Mista; Valores seguidos da mesma letra maiúscula, na vertical, não diferem estatisticamente entre si pelo teste de Tukey ao nível de $5 \%$ de probabilidade. Valores seguidos da mesma letra minúscula, na horizontal, não diferem estatisticamente entre si pelo teste de Tukey ao nível de $5 \%$ de probabilidade.

subtropicais, estando ligado, segundo Delitti (1984), ao impacto mecânico provocado pelas chuvas e pelos ventos, provocando assim um aumento na taxa de deposição. Já nas regiões frias o comportamento é ao contrário, onde a chegada do outono é que desencadeia o processo de derrubada do folhedo.

As estações outono, inverno e primavera não apresentaram diferenças estatísticas de produção de serapilheira entre os grupos florísticos. A estação verão obteve maior produção na FOM Típica, diferindo estatisticamente da Floresta de Locais Úmidos. Essa diferença foi verificada, devido, provavelmente, a grande produção da fração grimpas durante o verão na FOM Típica, o que não foi observado na Floresta de Locais Úmidos, uma vez que esse grupo apresenta reduzido número de indivíduos de Araucaria angustifolia, contribuindo assim com pouco material nessa fração. Em estudo realizado por Schumacher et al. (2004), em um povoamento formado por Araucaria angustifolia com 17 anos de idade, também foi encontrada maior produção de ramos aciculados (grimpas) dessa espécie nos meses de verão.

\section{Macronutrientes na serapilheira}

A análise estatística mostrou haver diferenças significativas nas concentrações de alguns macronutrientes da serapilheira depositada entre os grupos florísticos em suas respectivas frações (Tabela 4). Para Schumacher et al. (2004), o teor de nutrientes pode variar, para uma mesma espécie, em função do sítio e das características da planta, o que torna difícil a comparação entre povoamentos.

Em todas as frações de serapilheira, o potássio $(\mathrm{K})$ não apresentou diferença estatística entre os grupos florísticos. Da mesma forma, as frações galhos e sementes não apresentaram nenhum nutriente com concentração variando significativamente entre os grupos florísticos.

A Floresta de Locais Úmidos apresentou as maiores diferenças estatística entre os grupos florísticos para as diferentes frações. A fração folhas de folhosas obteve a maior concentração de nitrogênio $(\mathrm{N})$ para esse grupo florístico. Para a fração grimpas, as maiores concentrações foram observadas para o nitrogênio $(\mathrm{N})$, fósforo $(\mathrm{P})$, cálcio $(\mathrm{Ca})$ e enxofre $(\mathrm{S})$, porém apresentando a menor concentração para o magnésio $(\mathrm{Mg})$. Já para a fração sementes, a Floresta de Locais Úmidos obteve maiores concentrações para os nutrientes: N, $\mathrm{P}, \mathrm{Ca}$ e S.

Em relação à concentração de nutrientes entre as frações de serapilheira dentro de cada grupo florístico, pode-se observar que a fração sementes apresentou alta concentração de $\mathrm{P}$ em relação às demais frações da serapilheira em todos os grupos florísticos, o mesmo ocorrendo para K. A maior concentração de $\mathrm{P}$ e $\mathrm{K}$ na fração de material reprodutivo também foi observada por diversos autores (BRITEZ et al., 1992; CUNHA et al., 1993; VILELLA e PROCTOR, 1999). A fração sementes, entretanto, foi a que apresentou menor concentração de cálcio (Ca) em todos os grupos florísticos.

$\mathrm{Na}$ Floresta Secundária de Encosta, o Enxofre (S) teve a maior concentração para a fração grimpas, diferindo da fração folhas de folhosas, a qual obteve a menor concentração. Para os demais grupos florísticos, não foram observadas diferenças de concentração de $S$ entre as frações de serapilheira.

As concentrações médias dos diferentes macronutrientes, em cada grupo florístico, não apresentaram um comportamento sazonal claro, sendo que não foram observadas diferenças estatísticas para as concentrações dos nutrientes entre as estações do ano, com exceção da Floresta 
TABELA 4: Concentrações médias $\left(\mathrm{g} \cdot \mathrm{kg}^{-1}\right)$ dos macronutrientes nas diferentes frações de serapilheira em cada grupo florístico. FLONA de São Francisco de Paula, RS, 2007.

TABLE 4: Average concentrations $\left(\mathrm{g} \cdot \mathrm{kg}^{-1}\right)$ of the macronutrients in different fractions of litter in each floristic group. National Forest of São Francisco de Paula, RS state, 2007.

\begin{tabular}{|c|c|c|c|c|c|c|c|}
\hline \multirow{2}{*}{ Frações } & \multirow{2}{*}{ Grupo Florístico } & $\mathrm{N}$ & $\mathrm{P}$ & $\mathrm{K}$ & $\mathrm{Ca}$ & $\mathrm{Mg}$ & $\mathrm{S}$ \\
\hline & & \multicolumn{6}{|c|}{ g. $\mathrm{kg}^{-1}$} \\
\hline \multirow{3}{*}{$\begin{array}{l}\text { Folhas } \\
\text { folhosas }\end{array}$} & Fl. Secundária de Encosta & 10,65 b B & 0,61 a B & 2,50 a C & 10,29 a $\mathrm{AB}$ & 2,60 a $\mathrm{AB}$ & $0,91 \mathrm{aC}$ \\
\hline & FOM Típica & $10,69 \mathrm{bA}$ & 0,54 а в & 3,08 a в & 20,04 a A & $2,00^{\mathrm{a} \mathrm{B}}$ & 0,93 a A \\
\hline & Fl. de Locais Úmidos & 13,47 a A & 0,75 а в & 4,55 а в & $18,66^{\mathrm{aA}}$ & $2,06^{\text {a BC }}$ & $1,11^{\text {a A }}$ \\
\hline \multirow{3}{*}{ Grimpas } & Fl. Secundária de Encosta & $19,87^{\mathrm{bA}}$ & $0,73^{\mathrm{b} \mathrm{B}}$ & $6,60^{\mathrm{aAB}}$ & $9,98^{\mathrm{bAB}}$ & 3,07 a A & $1,71^{\mathrm{bA}}$ \\
\hline & FOM Típica & 22,12 ab A & $0,81 \mathrm{bAB}$ & 6,63 a $\mathrm{AB}$ & $13,21 \mathrm{ab} \mathrm{AB}$ & 3,11 a A & $1,73^{\mathrm{bA}}$ \\
\hline & Fl. de Locais Úmidos & 22,63 a A & 1,05 a B & 5,35 a B & 15,59 a $\mathrm{AB}$ & $2,85^{\mathrm{bA}}$ & $2,06^{\text {aA }}$ \\
\hline \multirow{3}{*}{ Galhos } & Fl. Secundária de Encosta & 11,99 а в & $0,46^{\text {a B }}$ & $2,66^{\mathrm{aC}}$ & $14,70^{\text {a } \mathrm{A}}$ & 2,08 a B & $1,17^{\text {a } B C}$ \\
\hline & FOM Típica & 11,73 a A & $0,55^{\text {a } \mathrm{B}}$ & 3,43 a $\mathrm{B}$ & 22,22 a A & $2,20^{\text {a } \mathrm{AB}}$ & $1,16^{\text {aA }}$ \\
\hline & Fl. de Locais Úmidos & $11,81^{\text {a A }}$ & $0,62^{\text {a } \mathrm{B}}$ & $2,48^{\text {a B }}$ & $18,09^{\text {a A }}$ & $1,58^{\mathrm{aC}}$ & $1,07^{\text {a A }}$ \\
\hline \multirow{3}{*}{ Sementes } & Fl. Secundária de Encosta & $13,50^{\mathrm{a}} \mathrm{AB}$ & 1,47 a A & 10,47 a A & 3,19 a C & 1,74 a B & 1,13 a $\mathrm{BC}$ \\
\hline & FOM Típica & 18,97 a A & 2,13 a A & $10,15^{\text {aA }}$ & 2,95 а в & $1,96^{\text {a } \mathrm{B}}$ & 1,54 a A \\
\hline & Fl. de Locais Úmidos & $21,75^{\text {aA }}$ & $2,81^{\text {a A }}$ & $11,65^{\text {aA }}$ & 2,23 a C & $1,75^{\text {a BC }}$ & $2,04{ }^{\mathrm{aA}}$ \\
\hline \multirow{3}{*}{ Miscelânea } & Fl. Secundária de Encosta & 16,93 ab $\mathrm{AB}$ & $0,88^{a b} \mathrm{~B}$ & $5,50^{\text {a } \mathrm{BC}}$ & $7,68^{\mathrm{b} \mathrm{BC}}$ & 2,39 a $\mathrm{AB}$ & $1,54 \mathrm{ab} \mathrm{AB}$ \\
\hline & FOM Típica & $14,51 \mathrm{bA}$ & 0,75 b в & $5,28 \mathrm{aAB}$ & $9,12 \mathrm{ab} \mathrm{AB}$ & $2,17 \mathrm{aAB}$ & $1,21 \mathrm{bA}$ \\
\hline & Fl. de Locais Úmidos & 22,97 a A & $1,37 \mathrm{aAB}$ & 5,80 а в & 10,44 а в & $2,47 \mathrm{aAB}$ & $1,88^{\text {a A }}$ \\
\hline
\end{tabular}

Em que: FL = Floresta; FOM = Floresta Ombrófila Mista; Médias seguidas da mesma letra minúscula, na vertical, não diferem estatisticamente entre si pelo teste de Tukey ao nível de 5\% de probabilidade. Comparação entre grupos florísticos, dentro de cada fração. Médias seguidas da mesma letra maiúscula, na vertical, não diferem estatisticamente entre si pelo teste de Tukey ao nível de 5\% de probabilidade. Comparação entre frações, dentro de cada grupo florístico.

de Locais Úmidos. Nesse grupo, a concentração de $\mathrm{N}$ foi significativamente maior na primavera, diferindo da concentração no outono e no inverno (Tabela 5).

A influência da pluviosidade na concentração de alguns nutrientes tem sido relatada por alguns autores. Em geral os nutrientes mais influenciados pela precipitação são K e N. Devido à alta mobilidade desses nutrientes na planta, em períodos de maior precipitação têm sido observadas baixas concentrações desses nos tecidos vegetais (BRITEZ, 1994; CUSTÓDIO-FILHO et al., 1996). Esse comportamento não foi observado no presente estudo, uma vez que, pode ter sido mascarado pela regularidade das chuvas durante as estações do ano no período de estudo, a qual foi observada nos dados climáticos obtidos pela própria Floresta Nacional, extraídos de relatório não publicado (IBAMA/ ICMBio, 2008).

Caldeira et al. (2007) encontraram teores médios de macronutrientes na ordem de, em g.kg${ }^{1}: \mathrm{N}=11,97 ; \mathrm{P}=0,68 ; \mathrm{K}=5,67 ; \mathrm{Ca}=6,61 ; \mathrm{Mg}=$ 0,95 e $\mathrm{S}=1,85$ em uma Floresta Ombrófila Mista Montana, no estado do Paraná. Comparando-se os teores de macronutrientes encontrados na floresta em estudo, observa-se que N, Ca e Mg apresentaram valores altos e $\mathrm{S}$ valores menores.

Da mesma forma que não foram verificadas diferenças estatísticas de produção total de serapilheira entre os grupos florísticos, também não foram observadas diferenças para a transferência total de nutrientes entre os grupos (Tabela 6). $\mathrm{O}$ retorno total estimado de macronutrientes foi de $358,57 \mathrm{~kg} \cdot \mathrm{ha}^{-1} \cdot$ ano $^{-1}$ para a FOM Típica, 284,25 $\mathrm{kg} \cdot \mathrm{ha}^{-1}$ ano $^{-1}$ para a Floresta de Locais úmidos e 256,80 kg.ha ${ }^{-1} \cdot$ ano $^{-1}$ para Floresta Secundária de Encosta. Esses valores estão dentro dos limites 205 e $411 \mathrm{~kg} / \mathrm{ha} /$ ano encontrados por Britez et al. (1992) e Sousa (2003), em Floresta Ombrófila Mista Submontana e Aluvial.

Os valores médios de $\mathrm{N}$ e Ca para os três grupos florísticos foram, respectivamente, $36,1 \%$ e $68,4 \%$ maiores dos encontrados por Britez et al. (1992), em uma floresta de araucária no Paraná, onde observaram as seguintes quantidades de $\mathrm{N}, \mathrm{P}$, K, Ca e Mg: 89,2; 5,8; 32,1; 62,4 e 15,9 kg.ha ${ }^{-1}$. ano, respectivamente. Em outro estudo, realizado em Floresta Ombrófila Mista Montana por Caldeira 
TABELA 5: Concentrações médias $\left(\mathrm{g} \cdot \mathrm{kg}^{-1}\right)$ dos macronutrientes nas estações do ano em cada grupo florístico. FLONA de São Francisco de Paula, RS, 2007.

TABLE 5: Average concentrations $\left(\mathrm{g} \cdot \mathrm{kg}^{-1}\right)$ of the macronutrients in the year seasons in each floristic group. National Forest of São Francisco de Paula, RS state, 2007.

\begin{tabular}{|c|c|c|c|c|c|c|c|}
\hline \multirow{2}{*}{ Grupo Florístico } & \multirow{2}{*}{ Estação } & \multicolumn{6}{|c|}{ Macronutrientes $\left(\mathrm{g} \cdot \mathrm{kg}^{-1}\right)$} \\
\hline & & $\mathrm{N}$ & $\mathrm{P}$ & $\mathrm{K}$ & $\mathrm{Ca}$ & $\mathrm{Mg}$ & $\mathrm{S}$ \\
\hline \multirow{4}{*}{$\begin{array}{l}\text { Floresta Secundária } \\
\text { de Encosta }\end{array}$} & Verão & $14,55^{\mathrm{a}}$ & $0,76^{\mathrm{a}}$ & $6,24^{\text {a }}$ & $8,30^{\text {a }}$ & $2,49^{\mathrm{a}}$ & $1,20^{\mathrm{a}}$ \\
\hline & Outono & $13,02^{\mathrm{a}}$ & $0,85^{\text {a }}$ & $6,33^{\text {a }}$ & $8,15^{\text {a }}$ & $2,31^{\text {a }}$ & $1,22^{\mathrm{a}}$ \\
\hline & Inverno & $15,36^{\mathrm{a}}$ & $0,64^{\text {a }}$ & $3,96^{\text {a }}$ & $13,71^{\mathrm{a}}$ & $2,31^{\mathrm{a}}$ & $1,38^{\mathrm{a}}$ \\
\hline & Primavera & $15,80^{\text {a }}$ & $0,90^{\text {a }}$ & $4,34^{\text {a }}$ & $8,62^{\text {a }}$ & $2,50^{\text {a }}$ & $1,42^{\mathrm{a}}$ \\
\hline \multirow{4}{*}{$\begin{array}{l}\text { FOM } \\
\text { Típica }\end{array}$} & Verão & $15,64^{\text {a }}$ & $0,78^{\text {a }}$ & $4,49^{a}$ & $15,15^{\text {a }}$ & $2,35^{\mathrm{a}}$ & $1,34^{\mathrm{a}}$ \\
\hline & Outono & $13,42^{\text {a }}$ & $0,81^{\mathrm{a}}$ & $5,79^{a}$ & $12,81^{\text {a }}$ & $2,30^{a}$ & $1,13^{\mathrm{a}}$ \\
\hline & Inverno & $13,85^{\mathrm{a}}$ & $0,82^{\text {a }}$ & $6,98^{\text {a }}$ & $13,40^{\mathrm{a}}$ & $2,25^{\text {a }}$ & $1,15^{a}$ \\
\hline & Primavera & $19,50^{\mathrm{a}}$ & $1,42^{\mathrm{a}}$ & $5,59^{\mathrm{a}}$ & $12,66^{\mathrm{a}}$ & $2,24^{a}$ & $1,63^{\mathrm{a}}$ \\
\hline \multirow{4}{*}{$\begin{array}{l}\text { Floresta de Locais } \\
\text { Úmidos }\end{array}$} & Verão & $19,53^{a b}$ & $1,19^{\mathrm{a}}$ & $6,40^{\text {a }}$ & $14,38^{\mathrm{a}}$ & $2,24^{\mathrm{a}}$ & $1,69^{\mathrm{a}}$ \\
\hline & Outono & $15,75^{\mathrm{b}}$ & $1,02^{\mathrm{a}}$ & $5,98^{\text {a }}$ & $14,03^{\mathrm{a}}$ & $1,93^{\text {a }}$ & $1,37^{\mathrm{a}}$ \\
\hline & Inverno & $15,31^{\mathrm{b}}$ & $1,08^{\text {a }}$ & $5,18^{\text {a }}$ & $13,70^{\mathrm{a}}$ & $2,02^{\text {a }}$ & $1,35^{\mathrm{a}}$ \\
\hline & Primavera & $23,50^{\mathrm{a}}$ & $1,97 \mathrm{a}$ & $6,30^{\mathrm{a}}$ & $9,89^{\mathrm{a}}$ & 2,38 a & $2,41^{a}$ \\
\hline
\end{tabular}

Em que: FOM = Floresta Ombrófila Mista; Médias seguidas da mesma letra, na vertical, não diferem estatisticamente entre si pelo teste de Tukey ao nível de $5 \%$ de probabilidade. Comparação entre estações, dentro de cada grupo florístico.

TABELA 6: Transferência estacional de macronutrientes pela serapilheira depositada nos três grupos florísticos na Floresta Ombrófila Mista. FLONA de São Francisco de Paula, 2007.

TABLE 6: Season transference of macronutrients by the litter deposited in the three floristic groups in the Mixed Rain Forest. National Forest of São Francisco de Paula, RS state, 2007.

\begin{tabular}{|c|c|c|c|c|c|c|c|c|}
\hline \multirow{2}{*}{ Grupo Florístico } & \multirow{2}{*}{ Estação } & \multicolumn{6}{|c|}{ Macronutrientes $\left(\mathrm{kg} \cdot \mathrm{ha}^{-1}\right)^{\mathrm{ns}}$} & \multirow{2}{*}{$\begin{array}{c}\text { Total } \\
\left(\mathrm{kg} \cdot \mathrm{ha}^{-1}\right)\end{array}$} \\
\hline & & $\mathrm{N}$ & $\mathrm{P}$ & $\mathrm{K}$ & $\mathrm{Ca}$ & $\mathrm{Mg}$ & $\mathrm{S}$ & \\
\hline \multirow{5}{*}{$\begin{array}{l}\text { Floresta } \\
\text { Secundária } \\
\text { de Encosta }\end{array}$} & Verão & 29,92 & 1,40 & 9,86 & 17,97 & 5,58 & 2,43 & 67,16 \\
\hline & Outono & 17,34 & 0,86 & 5,89 & 11,99 & 3,48 & 1,59 & 41,15 \\
\hline & Inverno & 27,09 & 1,26 & 6,54 & 28,61 & 4,34 & 2,39 & 70,23 \\
\hline & Primavera & 33,86 & 1,79 & 10,51 & 22,50 & 6,48 & 3,12 & 78,26 \\
\hline & Total & 108,21 & 5,32 & 32,80 & 81,08 & 19,88 & 9,52 & 256,80 \\
\hline \multirow{5}{*}{$\begin{array}{l}\text { FOM } \\
\text { Típica }\end{array}$} & Verão & 53,54 & 2,03 & 13,79 & 47,95 & 7,60 & 4,36 & 129,27 \\
\hline & Outono & 30,98 & 1,42 & 10,78 & 26,07 & 4,86 & 2,48 & 76,58 \\
\hline & Inverno & 21,66 & 1,01 & 8,14 & 17,70 & 3,52 & 1,70 & 53,73 \\
\hline & Primavera & 41,97 & 1,92 & 13,87 & 31,55 & 6,18 & 3,49 & 98,98 \\
\hline & Total & 148,16 & 6,38 & 46,58 & 123,26 & 22,16 & 12,03 & 358,57 \\
\hline \multirow{6}{*}{$\begin{array}{l}\text { Floresta de Locais } \\
\text { Úmidos }\end{array}$} & Verão & 28,10 & 1,44 & 7,54 & 28,89 & 3,47 & 2,38 & 71,84 \\
\hline & Outono & 20,83 & 1,09 & 5,36 & 27,28 & 2,85 & 1,75 & 59,15 \\
\hline & Inverno & 19,58 & 1,02 & 4,20 & 30,64 & 3,13 & 1,71 & 60,29 \\
\hline & Primavera & 39,20 & 2,63 & 17,31 & 25,64 & 5,01 & 3,18 & 92,97 \\
\hline & Total & 107,72 & 6,18 & 34,41 & 112,45 & 14,46 & 9,02 & 284,25 \\
\hline & Média & 121,36 & 5,96 & 37,93 & 105,06 & 18,83 & 10,19 & 299,87 \\
\hline
\end{tabular}

Em que: $\mathrm{FOM}=$ Floresta Ombrófila Mista; ${ }^{\text {ns }}=$ não significativo, pelo teste de Tukey ao nível de $5 \%$ de probabilidade. Comparação entre grupos, para o total e para o total de cada nutriente. 
et al. (2007), foram observados os seguintes fluxos $\left(\right.$ em kg ha ${ }^{-1}$ ano $\left.^{-1}\right)$ : $\mathrm{N}=95,66 ; \mathrm{P}=5,43 ; \mathrm{K}=45,32$; $\mathrm{Ca}=36,84 ; \mathrm{Mg}=7,56$ e $\mathrm{S}=14,75$. Na serapilheira de florestas tropicais no Brasil, Dantas e Phillipson (1989), apresentam as seguintes faixas de N, P, K, Ca e Mg, consecutivamente: 74-156; 1-3,4; 13-26; 18-76 e $1-29$ kg.ha- ${ }^{-1}$.ano ${ }^{-1}$.

Os maiores retornos dos macronutrientes da serapilheira depositada variou conforme o grupo florístico. Na Floresta Secundária de Encosta e na FOM Típica a ordem foi $\mathrm{N}>\mathrm{Ca}>\mathrm{K}>\mathrm{Mg}>\mathrm{S}>\mathrm{P}$. Já para a Floresta de Locais Úmidos, a ordem foi $\mathrm{Ca}$ $>\mathrm{N}>\mathrm{K}>\mathrm{Mg}>\mathrm{S}>\mathrm{P}$. Isso corrobora com Vitousek (1984), o qual sugere ser o fósforo o elemento mais limitante nas florestas tropicais.

A transferência estacional dos macronutrientes mostrou-se variável em todos os grupos florísticos. A Floresta Secundária de Encosta não seguiu o mesmo comportamento da deposição de serapilheira, apresentando transferência maior na primavera $>$ inverno $>$ verão $>$ outono. Já para os demais grupos florísticos a ordem de transferência seguiu a da deposição da serapilheira, ou seja, a taxa de nutrientes que é devolvida ao solo florestal foi diretamente proporcional a produção de serapilheira, dependendo muito mais da quantidade de material que é depositado no solo do que do próprio teor dos nutrientes.

\section{CONCLUSÕES}

Embora tenham sido observadas diferenças de florística e estrutura entre os grupos florísticos analisados, não foram verificadas diferenças na produção total de serapilheira nos mesmos. Da mesma forma, não foram observadas diferenças na transferência total de nutrientes entre os grupos. Para a deposição estacional de serapilheira entre os grupos florísticos, a única diferença encontrada foi a maior deposição na estação verão para o grupo FOM Típica em relação à Floresta de Locais Úmidos, sendo este dado devido, principalmente, a grande diferença de deposição da fração grimpas entre esses grupos florísticos.

Para a Floresta Secundária de Encosta e para a FOM Típica, o nitrogênio foi o elemento que apresentou o maior retorno, seguido do cálcio. Já para a Floresta de Locais Úmidos, o cálcio mostrou-se o elemento de maior retorno, seguido pelo nitrogênio. Em ambos os grupos a ordem de transferência dos demais nutrientes foi: $\mathrm{K}>\mathrm{Mg}>\mathrm{S}$ $>$ P.
Os grupos florísticos Floresta Secundária de Encosta e Floresta de Locais Úmidos apresentaram a mesma estacionalidade de produção de serapilheira, ou seja, seguiu a ordem decrescente primavera $>$ verão $>$ inverno $>$ outono. Já para o grupo FOM Típica a ordem foi verão $>$ primavera $>$ outono $>$ inverno.

\section{REFERÊNCIAS BIBLIOGRÁFICAS}

BACKES, A.; PRATES, F. L.; VIOLA, M. G. Produção de serapilheira em Floresta Ombrófila Mista, em São Francisco de Paula, Rio Grande do Sul, Brasil. Acta Botânica Brasílica, Porto Alegre, v. 19, n. 1, p. 155-160, jan./abr. 2005.

BRITEZ, R. M. Ciclagem de nutrientes minerais em duas florestas da planície litorânea da Ilha do Mel, Paranaguá, PR. 1994. 240 f. Dissertação (Mestrado em Engenharia Florestal)-Universidade Federal do Paraná, Curitiba, 1994.

BRITEZ, R. M. et al. Deposição estacional de serapilheira e macronutrientes em uma floresta de Araucária, São Mateus do Sul, Paraná. Revista do Instituto Florestal, São Paulo, v. 4, n. 3, p. 766772, 1992.

BRAY, J. R.; GORHAM, E. Litter production in forests of the world. Advances in Ecological Research, London, v. 2, p. 101-157, 1964.

CALDEIRA, M. V. W. et al. Quantificação de serapilheira e de nutrientes - Floresta Ombrófila Mista Montana - Paraná. Rev. Acad., Curitiba, v. 5, n. 2, p. 101-116, 2007.

CALDEIRA, M. V. W. et al. Quantificação de serapilheira e de nutrientes em uma Floresta Ombrófila Densa. Semina: Ciências Agrárias, Londrina, v. 29, n. 1, p. 53-68, jan./mar. 2008.

CALVI, G. P.; PEREIRA, M. G.; ESPÍNULA JUNIOR, A. Produção de serapilheira e aporte de nutrientes em áreas de floresta atlântica em Santa Maria de Jetibá, ES. Ciência Florestal, Santa Maria, v. 19, n. 2, p. 131-138, abr./jun. 2009.

CHAMI, L. B. Vegetação e mecanismos de regeneração natural em diferentes ambientes da Floresta Ombrófila Mista na FLONA de São Francisco de Paula, RS. 2008. 121 f. Dissertação (Mestrado em Engenharia Florestal)-Universidade Federal de Santa Maria, Santa Maria, 2008.

CUNHA, G. C. et al. Dinâmica nutricional em floresta estacional decidual com ênfase aos minerais provenientes da deposição da serapilheira. Ciência Florestal, Santa Maria, v. 3, n. 1, p. 35-64, 1993. CUSTÓDIO FILHO, A. et al. Produção de 
serapilheira e o retorno de macronutrientes em floresta pluvial atlântica - Estação Biológica de Boracéia (São Paulo - Brasil). Revista do Instituto Florestal, São Paulo, v. 8, n. 1, p.1-16, jan./jun.1996.

DANTAS, M.; PHILLIPSON, J. Litterfall e litter nutrient content in primary and secondary Amazonian 'terra firme' rain forest. Journal of Tropical Ecology, Cambridge, v. 5, n. 1, p. 27/36, Feb. 1989.

DELITTI, W. B. C. Aspectos comparativos da ciclagem de nutrientes minerais na mata ciliar, no campo cerrado e na floresta implantada de Pinus elliottii Engelm var. elliottii (Mogi-Guaçu, SP). 1984. 132 f. Tese (Doutorado em Biociências) Universidade de São Paulo, Instituto de Biociências, São Paulo, 1984.

FACELLI, J. M.; PICKETT, S. T. A. Plant litter: its dynamics and effects on plant community structure. The Botanical Review, New York, v. 57, p. 1-32, 1991.

FIGUEIREDO FILHO, A. et al. Avaliação estacional da deposição de serapilheira em uma Floresta Ombrófica Mista localizada no sul do estado do Paraná. Ciência Florestal, Santa Maria, v.13, n.1, p.11-18, 2003.

FIGUEIREDO FILHO, A. et al. Produção estacional de serapilheira em uma Floresta Ombrófica Mista na Floresta Nacional de Iratí (PR). Ambiência, Guarapuava, v. 1, n. 2, p. 259-269, 2005.

FLOSS, P. A.; CALDATO, S. L.; BOHNER, J. A. M. Produção e decomposição de serapilheira na Floresta Ombrófila Mista da reserva florestal da EPAGRI/EMBRAPA de Caçador, SC. Revista Agropecuária Catarinense, Florianópolis, v. 12, n. 2, p. 19-22, 1999.

GOLLEY, F. B. Ciclagem de minerais em um ecossistema de Floresta Tropical Úmida. São Paulo: EPU, 1975. 256 p.

GOLLEY, F. B. et al. Ciclagem de minerais em um ecossistema de floresta tropical úmida. São Paulo: Pedagógica e Universitária, 1978. 256 p.

GOMES, J. F. et al. Classificação e crescimento de unidades de vegetação em Floresta Ombrófila Mista, São Francisco de Paula, RS. Ciência Florestal, Santa Maria, v. 18, n. 1, p. 93-107, 2008. IBAMA/ICMBio, Temperatura e precipitação pluvial de 2000 a 2008 na Floresta Nacional de São Francisco de Paula, RS. São Francisco de Paula: 2008. 115 p. (Relatório não publicado)

KOEHLER, W. C. Variação estacional de deposição de serapilheira e de nutrientes em povoamentos de Pinus taeda na região de Ponta Grossa - PR. 1989. 138 f. Tese (Doutorado em Ciências Florestais)-Universidade Federal do Paraná, Curitiba, 1989.

LONGHI, S. J. et al. Classificação e caracterização de estágios sucessionais em remanescentes de Floresta Ombrófila Mista na FLONA de São Francisco de Paula, RS, Brasil. Ciência Florestal, Santa Maria, v. 16, n. 2, p. 113-125, 2006.

LONGHI, S. J. et al. Fatores ecológicos determinantes na ocorrência de Araucaria angustifolia e Podocarpus lambertii, na Floresta Ombrófila Mista da FLONA de São Francisco de Paula, RS, Brasil. Ciência Rural, Santa Maria, v. 40, n. 1, p. 57-63, 2010.

MOREIRA, F. M. S.; SIQUEIRA, J. O. Microbiologia e bioquímica do solo. Lavras: Ed. UFLA, 2002. $626 \mathrm{p}$.

MORENO, J. A. Clima do Rio Grande do Sul. Porto Alegre: Secretaria da Agricultura, 1961. 42 p. NARVAES, I. da S.; LONGHI, S. J.; BRENA, D. A. Florística e classificação da regeneração natural em Floresta Ombrófila Mista na Floresta Nacional de São Francisco de Paula, RS. Ciência Florestal, Santa Maria, v. 18, n. 2, p. 233-245, 2008.

PINTO, S. I. C. et al. Ciclagem de nutrientes em dois trechos de floresta estacional semidecidual na reserva florestal Mato do Paraíso em Viçosa, MG, Brasil. Revista Árvore, Viçosa, v. 33, n. 4, p. 653663, 2009.

RIBEIRO, S. B. et al. Diversidade e classificação da comunidade arbórea da Floresta Ombrófila Mista da FLONA de São Francisco de Paula, RS. Ciência Florestal, Santa Maria, v. 17, n. 2, p. 101108, 2007.

RIO GRANDE DO SUL. Governo do Estado. Secretaria Estadual do Meio Ambiente. Inventário florestal contínuo do Rio Grande do Sul. Porto Alegre: SEMA, 2002. 706 p. (Relatório Final).

SANQUETTA, C. R. et al. Estrutura vertical de um fragmento de Floresta Ombrófila Mista no Centro-Sul do Paraná. Revista Ciências Exatas e Naturais, Iratí, v. 3, n. 1, p. 59-73, 2001.

SCHUMACHER, M. V. et al. Produção de serapilheira em uma floresta de Araucaria angustifolia (Bertol.) Kuntze no município de Pinhal Grande-RS. Revista Árvore, Viçosa, v. 28, n. 1, p. 29-37, 2004.

SILVA, F. A. S. E.; AZEVEDO, C. A. V. Versão do programa computacional Assistat para o sistema operacional Windows. Revista Brasileira de Produtos 
Agroindustriais, Campina Grande, v. 4, n. 1, p. 71-78, 2002.

SOUSA, S. G. A. Produção e decomposição de serapilheira de uma floresta ombrófila mista aluvial, Rio Barigui, Araucária, PR. 2003. 127 f. Tese (Doutorado em Ciências Florestais)-Setor de Ciências Agrárias, Universidade Federal do Paraná, Curitiba, 2003.

STRECK, E. V. et al. Solos do Rio Grande do Sul. 2. ed. Porto Alegre: EMATER/RS-ASCAR, 2008. $222 \mathrm{p}$.
TEDESCO, M. J. et al. Análise de solo, plantas e outros materiais. Porto Alegre: Departamento de Solos - UFRGS, 1995. 118 p. (Boletim Técnico). VILLELA, D.; PROCTOR, J. Litterfall Mass, chemistry, and nutrient retranslocation in a monodominant forest on Maracá Island, Roraima, Brazil. Biotropica, Washington, v. 31, n. 2, p. 198211, 1999.

VITOUSEK, P. M. Litterfall, nutrient cycling, and nutrient limitation in tropical forests. Ecology, Ithaca, v. 65, n. 1, p. 285-298, 1984. 